\title{
Optimizing accuracy and precision with motion correction of PET myocardial blood flow measurements
}

\author{
Alexis Poitrasson-Rivière, PhD, ${ }^{a}$ and Venkatesh L. Murthy, MD, PhD ${ }^{b}$ \\ a INVIA Medical Imaging Solutions, Ann Arbor, MI \\ b Division of Cardiovascular Medicine, Department of Internal Medicine and Frankel Cardiovas- \\ cular Center, University of Michigan, Ann Arbor, MI
}

Received Oct 2, 2019; accepted Oct 2, 2019

doi: 10.1007/s12350-019-01927-1

\section{See related article pp. 1718-1725}

\section{INTRODUCTION}

The well-validated diagnostic and prognostic value of quantitative estimates of myocardial blood flow (MBF) and flow reserve (MFR) derived from positron emission tomography ${ }^{1-5}$ have generated much enthusiasm for clinical implementation. Quantification of MBF at peak hyperemic stress and MFR can refine referrals for invasive angiography and may potentially improve selection of patients for revascularization. ${ }^{6,7}$ However, in order to apply these population data in a reliable manner to the management of individual patients, optimization of precision and accuracy is required. ${ }^{8}$ Patient motion effects are a major driver of both imprecision and inaccuracy. Work by Otaki et al in the present issue of the Journal of Nuclear Cardiology aims to address this issue. ${ }^{9}$

\section{BACKGROUND}

Quantification of MBF from PET myocardial perfusion imaging (MPI) is generally accomplished by recording data in list mode starting at the time of injection. These data are reconstructed into dynamic image series which consist of a sequence of snapshot images showing how the radiotracer mixed with the

Reprint requests: Alexis Poitrasson-Rivière, PhD, INVIA Medical Imaging Solutions, 3025 Boardwalk Dr., Suite 200, Ann Arbor, MI 48108, USA; apoitrasson@inviasolutions.com

J Nucl Cardiol 2021;28:1726-9.

$1071-3581 / \$ 34.00$

Copyright (c) 2019 American Society of Nuclear Cardiology. blood transits through the cardiac chambers (blood pool phase) and distributes into the myocardial tissue (tissue phase). These time series are usually reconstructed with short time frames early as the tracer is in the blood pool phase and with longer frames in the tissue phase to improve count statistics and reduce reconstruction time and storage requirements. ${ }^{10}$ Motion can occur within and between these frames in periodic and non-periodic fashion due to respiration and patient movement. An example of motion and its effect on MBF is shown in Figure 1, extracted from Lee et al. ${ }^{11}$

Several prior studies have demonstrated that motion is a major source of error in the quantification of MBF and MFR, ${ }^{11-13}$ summarized in Table 1. Furthermore, meaningful motion is common (seen in $65 \%$ of scans in a sizable clinical sample) and may cause alarmingly large errors as high as $500 \%$ in severe cases. ${ }^{14}$ More recently, our group analyzed a population of 225 sequential patients who underwent rest-stress $\mathrm{Rb}-82$ PET. ${ }^{11}$ All studies were motion-corrected by expert physician readers. Results demonstrated a notable regional impact of motion correction in the RCA territory (18.9\% average difference), particularly in the blood pool phase, where motion can have major impact on MBF calculations. An illustrative case is provided in Figure 1. This regional finding was further observed by Armstrong et al, with a 23\% median change in the RCA territory for cases with severe motion, although it was dominated by a $65 \%$ median difference in the apical and mid-anterior segments, which was blamed on tissuephase motion caused by adenosine. ${ }^{15}$

\section{ACCURACY AND PRECISION}

Prior studies have clearly shown the necessity for motion correction to obtain accurate MBF and MFR estimates. However, manual strategies may result in 
A

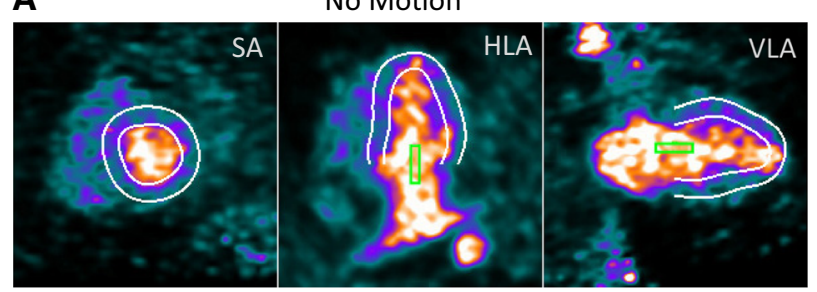

C

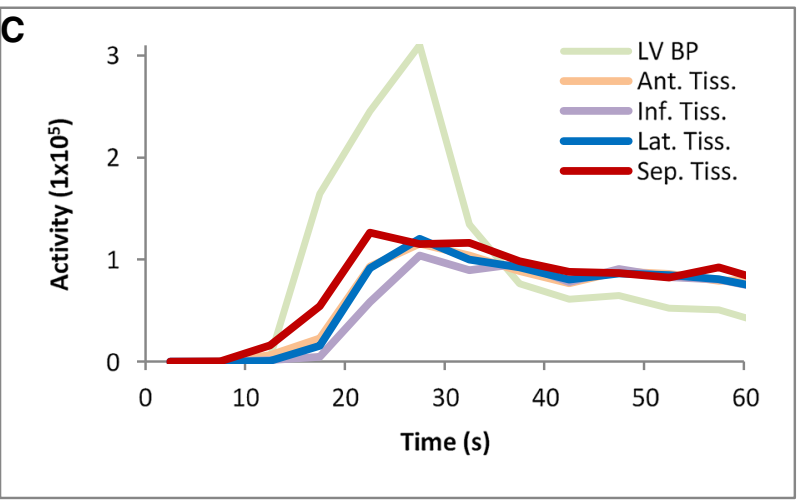

E

Stress MBF

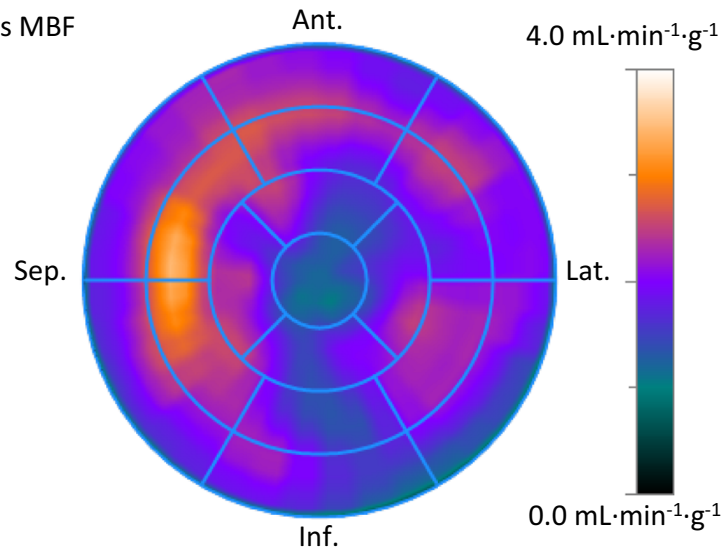

B

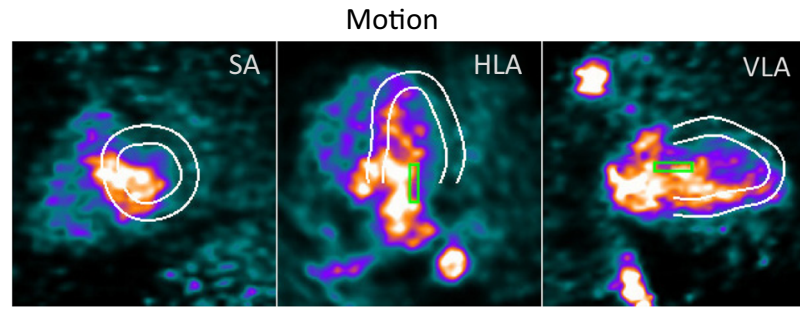

D

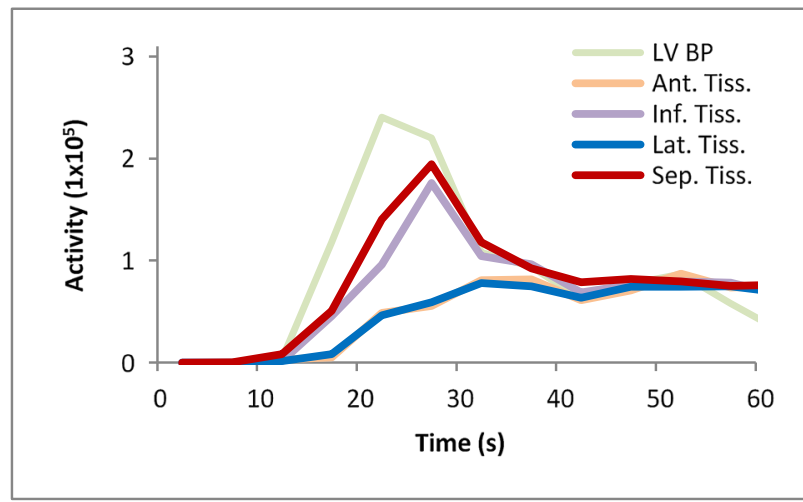

$\mathbf{F}$

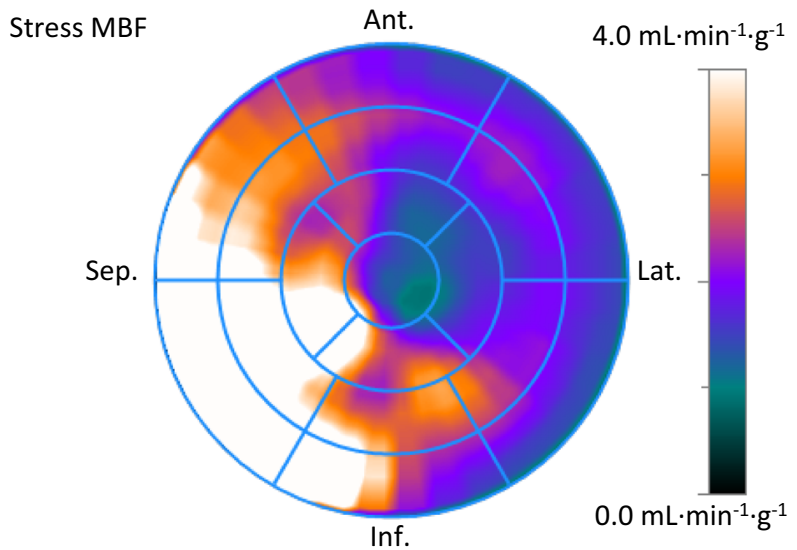

Figure 1. Example of motion in the blood pool phase inducing error on stress MBF from Lee et $\mathrm{al}^{11}$.

decreased precision as user input generally introduces variability. Otaki et al, in their present study, show that with manual motion correction performed by welltrained operators the test-retest coefficient of variation (CV) for MBF decreases from $16 \%$ to $9 \%$. This repeatability study shows that the potential added variability of manual motion correction is offset by the improvement in accuracy which results in matching testretest MBF estimates. Importantly, they report a low inter-user variability $\mathrm{CV}$ of $5 \%$ on motion-corrected studies. The excellent results suggest that it is possible to obtain highly repeatable motion correction results within and between operators. The study does however have limitations, as only rest datasets were analyzed whereas the literature has shown that motion is more prevalent and severe during stress. ${ }^{11,13}$

What is unknown is whether this level of consistency can be routinely achieved at less experienced, high-volume sites. Inconsistent manual motion correction would not only decrease reproducibility, but could reduce accuracy of estimates, particularly in scans without severe motion. Further real-world studies involving multiple sites would be required to understand the magnitude of this potential challenge. Regardless, it appears certain that skill and training in manual motion correction are additional critical challenges for clinical generalization of quantitative cardiac PET MPI. 
Table 1. Recapitulatory table of dynamic motion studies in the literature

\begin{tabular}{lllll}
\hline Study & N & Tracer & $\begin{array}{c}\text { Global percent } \\
\text { difference } \\
\text { (MBF/MFR) }\end{array}$ & $\begin{array}{c}\text { Regional percent } \\
\text { difference } \\
\text { (MBF/MFR) }\end{array}$ \\
\hline Koshino et al $(2012)^{12}$ & $9^{\mathrm{a}}$ & ${ }^{15} \mathrm{O}-$ Water & $7.7 \%$ & $25.1 \%^{\mathrm{c}}$ \\
Yu et al $(2016)^{13}$ & 7 & ${ }^{82} \mathrm{Rb}$ & $15 \% / 19 \%$ & $\mathrm{~N} / \mathrm{A}$ \\
Lee et al $(2018)^{11}$ & 225 & ${ }^{82} \mathrm{Rb}$ & $4.7 \% / 1.9 \%$ & $8.0 \% / 6.3 \%^{\mathrm{d}}$ \\
Otaki et al $(2019)^{9}$ & $21^{\mathrm{b}}$ & ${ }^{82} \mathrm{Rb}$ & $2.9 \%$ & $2.9 \%^{\mathrm{e}}$ \\
\hline
\end{tabular}

The percent differences are between motion-corrected values and non-corrected values. When available, stress MBF was used over rest $\mathrm{MBF}$

${ }^{\text {a}}$ Rest only studies with significant motion

${ }^{\text {b Rest only studies }}$

${ }^{\mathrm{C}}$ Average MBF difference from a 9-segment model

${ }^{\mathrm{d}}$ Average $\mathrm{MBF} / \mathrm{MFR}$ difference from 3 vascular regions

e Difference of the average MBF from 3 vascular regions

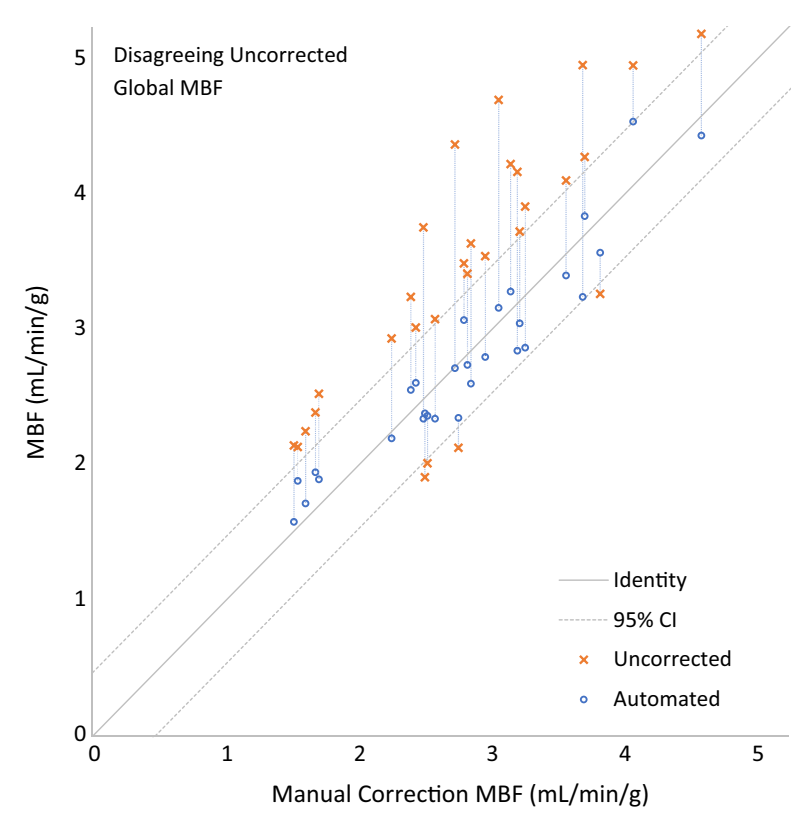

Figure 2. Visualization of the improvements made by automatic motion correction on uncorrected MBF outside of the limits of agreement (95\% confidence interval) from Lee et $\mathrm{al}^{16}$.

\section{CHALLENGE AND SOLUTION}

If optimal motion correction is essential to achieving maximal accuracy but manual motion correction decreases precision and requires training and experience to avoid unintended increases in errors, what is the solution? We have developed a fully automated motion correction algorithm for dynamic image series based on normalized gradient fields. ${ }^{16}$ Figure 2 highlights how the algorithm successfully improves the agreement for non-corrected studies that fell outside the $95 \%$ confidence interval from the physician-corrected reference. The algorithm correlated well with expert readers and rarely requires substantial manual corrections or editing. As a result, correlations between MBF and MFR values obtained by two technologists editing automated motion correction images $(\mathrm{CV}=4 \%)$ is meaningfully better than uncorrected images $(\mathrm{CV}=16 \%) .{ }^{17}$

Regardless of the approach used, the evidence in favor of motion correction is substantial and should now be standard practice for all dynamic PET MPI studies. We applaud Otaki et al for their important contribution and encourage the field to continue work in this area.

\section{Disclosure}

A. Poitrasson-Rivière is an employee of INVIA Medical Imaging Solutions. V.L. Murthy has received research funding from Siemens Medical Imaging and research support from INVIA Medical Imaging Solutions. He has served as an advisor to and owns stock options in Ionetix. He has received payment for expert witness testimony on behalf of Jubilant Draximage. He has served as an advisor to Curium and owns stock in General Electric and Cardinal Health. His research is supported by grants from the National Heart, Lung, and Blood Institute (R01HL136685) and National Institute on Aging (R01AG059729).

\section{References}

1. Naya M, Murthy VL, Taqueti VR, et al. Preserved coronary flow reserve effectively excludes high-risk coronary artery disease on angiography. J Nucl Med 2014;55:248-55. https://doi.org/10.2967/ jnumed.113.121442. 
2. Murthy VL, Naya M, Foster CR, et al. Improved cardiac risk assessment with noninvasive measures of coronary flow reserve. Circulation 2011;124:2215-24. https://doi.org/10.1161/CIRCULA TIONAHA.111.050427.

3. Murthy VL, Bateman TM, Beanlands RS, et al. Clinical quantification of myocardial blood flow using PET: joint position paper of the SNMMI Cardiovascular Council and the ASNC. J Nucl Cardiol 2017. https://doi.org/10.1007/s12350-017-1110-x.

4. Ziadi MC, Dekemp RA, Williams KA, et al. Impaired myocardial flow reserve on rubidium-82 positron emission tomography imaging predicts adverse outcomes in patients assessed for myocardial ischemia. J Am Coll Cardiol 2011;58:740-8. https://d oi.org/10.1016/j.jacc.2011.01.065.

5. Farhad H, Dunet V, Bachelard K, et al. Added prognostic value of myocardial blood flow quantitation in rubidium- 82 positron emission tomography imaging. Eur Hear J 2013;14:1203-10. h ttps://doi.org/10.1093/ehjci/jet068.

6. Patel KK, Spertus JA, Chan PS, et al. Myocardial blood flow reserve assessed by positron emission tomography myocardial perfusion imaging identifies patients with a survival benefit from early revascularization. Eur Heart J 2019. https://doi.org/10.1093/e urheartj/ehz389.

7. Gould KL, Johnson NP, Roby AE, et al. Regional, artery-specific thresholds of quantitative myocardial perfusion by PET associated with reduced myocardial infarction and death after revascularization in stable coronary artery disease. J Nucl Med 2019;60:4107. https://doi.org/10.2967/jnumed.118.211953.

8. Moody JB, Lee BC, Corbett JR, et al. Precision and accuracy of clinical quantification of myocardial blood flow by dynamic PET: a technical perspective. J Nucl Cardiol 2015. https://doi.org/10. 1007/s12350-015-0100-0.

9. Otaki Y, Lassen ML, Manabe O, et al. Short-term repeatability of myocardial blood flow using 82Rb PET/CT: the effect of arterial input function position and motion correction. J Nucl Cardiol 2019. https://doi.org/10.1007/s12350-019-01888-5.
10. Lee BC, Moody JB, Weinberg RL, et al. Optimization of temporal sampling for 82rubidium PET myocardial blood flow quantification. J Nucl Cardiol 2017;24:1517-29. https://doi.org/10.1007/ s12350-017-0899-7.

11. Lee BC, Moody JB, Poitrasson-Rivière A, et al. Blood pool and tissue phase patient motion effects on ${ }^{82}$ rubidium PET myocardial blood flow quantification. J Nucl Cardiol 2018. https://doi.org/10. 1007/s12350-018-1256-1.

12. Koshino K, Watabe H, Enmi J, et al. Effects of patient movement on measurements of myocardial blood flow and viability in resting 15O-water PET studies. J Nucl Cardiol 2012;19:524-33. https://d oi.org/10.1007/s12350-012-9522-0.

13. Yu Y, Chan C, Ma T, et al. Event-by-event continuous respiratory motion correction for dynamic PET imaging. J Nucl Med 2016;57:1084-90. https://doi.org/10.2967/jnumed.115.167676.

14. Hunter CRRN, Klein R, Beanlands RS, deKemp RA. Patient motion effects on the quantification of regional myocardial blood flow with dynamic PET imaging. Med Phys 2016;43:1829-40. h ttps://doi.org/10.1118/1.4943565.

15. Armstrong IS, Memmott MJ, Saint KJ, et al. Assessment of motion correction in dynamic rubidium-82 cardiac PET with and without frame-by-frame adjustment of attenuation maps for calculation of myocardial blood flow. J Nucl Cardiol 2019. https://doi.org/10. 1007/s12350-019-01834-5.

16. Lee BC, Moody JB, Poitrasson-Rivière A, et al. Automated dynamic motion correction using normalized gradient fields for 82rubidium PET myocardial blood flow quantification. J Nucl Cardiol 2018. https://doi.org/10.1007/s12350-018-01471-4.

17. Poitrasson-Rivière A, Moody JB, Hagio T, et al. Reducing motioncorrection-induced variability in ${ }^{82}$ rubidium myocardial blood flow quantification. J Nucl Cardiol 2019. https://doi.org/10.1007/ s12350-019-01911-9.

Publisher's Note Springer Nature remains neutral with regard to jurisdictional claims in published maps and institutional affiliations. 